Short communication

\title{
Dried extracts of Encholirium spectabile (Bromeliaceae) present antioxidant and photoprotective activities in vitro
}

\author{
Raimundo Gonçalves de Oliveira Jr., Grasielly Rocha Souza, Amanda Leite Guimarães, \\ Ana Paula de Oliveira, Amanda Caroline Silva Morais, Edigênia Cavalcante da Cruz Araújo, \\ Xirley Pereira Nunes, Jackson Roberto Guedes da Silva Almeida* \\ Center for Studies and Research of Medicinal Plants (NEPLAME), Federal University of San Francisco Valley, 56.304-205 Petrolina, Pernambuco, Brazil
}

\section{A R T I C L E I N F O}

\section{Article history:}

Received 16 June 2013

Accepted 21 August 2013

Available online 6 September 2013

\section{Keywords:}

Antioxidant properties

Bromeliaceae

Encholirium spectabile

Medicinal plants

Photoprotection

\begin{abstract}
A B S T R A C T
The antioxidant and photoprotective activities of dried extracts from the leaves of Encholirium spectabile were investigated. It was also evaluated the total phenolic and flavonoid contents by the Folin-Ciocalteu and aluminum chloride methods, respectively. Antioxidant activities of the extracts were evaluated by using of 2,2-diphenyl-1-picrylhydrazil (DPPH) radical scavenging and $\beta$-carotene-linoleic acid bleaching and compared with ascorbic acid, butylated hydroxyanisole (BHA) and butylated hydroxytoluene (BHT) used as reference compounds. The photoprotective effect was evaluated by the spectrophotometric method. The most significant total phenolic and flavonoid contents was of $188.50 \pm 27.50 \mathrm{mg}$ of gallic acid equivalent/g and $129.70 \pm 4.59 \mathrm{mg}$ of catechin equivalent/g, respectively, for chloroform fraction $\left(\mathrm{Es}-\mathrm{CHCl}_{3}\right)$. The Es- $\mathrm{CHCl}_{3}$ also presented the best antioxidant activity $\left(\mathrm{IC}_{50} 25.35 \pm 4.35 \mu \mathrm{g} / \mathrm{ml}\right.$ ) for DPPH scavenging. The ethanol extract (Es-EtOH), Es- $\mathrm{CHCl}_{3}$ and the fraction ethyl acetate (Es-AcOEt) showed characteristic absorption bands in regions UVB and UVA in a concentration-dependent manner. $\mathrm{Es}-\mathrm{CHCl}_{3}$ presented the highest sun protection factor SPF $(8.89 \pm 2.11)$. It shows the possibility to use this extract as sunscreen in pharmaceutical preparations.
\end{abstract}

Copyright $\odot$ 2013, InPharm Association, Published by Reed Elsevier India Pvt. Ltd. All rights reserved.

\section{Introduction}

Currently, the damage caused by ultraviolet radiation (UV) has become the focus of several studies. This is because ultraviolet radiation from the sun incidence is able to promote oxidative stress and inflammatory processes. The effects can vary according to the UV region of the electromagnetic spectrum, which can be divided in three regions: ultraviolet A (UVA - from 320 to $400 \mathrm{~nm}$ ); ultraviolet B (UVB - from 290 to $320 \mathrm{~nm}$ ) and ultraviolet C (UVC from 200 to $290 \mathrm{~nm}$ ). UVC radiation is filtered by the atmosphere before reaching earth. UVB radiation is not completely filtered out by the ozone layer and is responsible for the damage due to sunburn. UVA radiation reaches the deeper layers of the epidermis and dermis and provokes the premature aging of the skin. Ultraviolet radiations have been implicated as a causative factor of skin cancer. $^{1}$

The effectiveness of a sunscreen is measured as a function of their sun protection factor (SPF), which indicates how many times

\footnotetext{
* Corresponding author.

E-mail address: jackson.guedes@univasf.edu.br (J.R.G.S. Almeida).
}

the time of exposure to the sun without the risk of erythema can be increased with the use of protective. The higher SPF provides greater protection to the skin. It is noteworthy that the SPF is defined as a function of UVB radiation that causes erythema. ${ }^{2}$ The necessity to provide high sun protection factor (SPF) and screening efficiency against both ultraviolet A (UVA) and ultraviolet B (UVB) wavelengths has led to the development of sunscreen formulations with multiple added sunscreen chemicals. ${ }^{1}$

Encholirium spectabile belongs to Bromeliaceae family and is popularly known in Brazilian Caatinga as "macambira de flecha" and "macambira de pedra". ${ }^{3}$ Previous study realized by our research group demonstrated that the ethanolic extract of E. spectabile has gastroprotective activity against gastric mucosal damage induced by ethanol, $\mathrm{HCl} /$ ethanol, ibuprofen, ischemia and reperfusion, which suggests that the extract may activate cytoprotective mechanisms that increase the release of prostaglandins. ${ }^{4}$ It was also observed that crude extracts from the leaves of $E$. spectabile have antioxidant and antibacterial properties. $^{5}$

The aim of this study was to evaluate the antioxidant and photoprotective potential of dried extracts of E. spectabile aiming the developing of a new cosmetic product. 


\section{Material and methods}

\subsection{Plant material}

The leaves of E. spectabile Mart. ex Schult. f. were collected in the city of Petrolina (Coordinates: S $09^{\circ} 07^{\prime} 30^{\prime \prime}$; W $40^{\circ} 26^{\prime} 00^{\prime \prime}$ ), State of Pernambuco, Brazil, in January of 2010. The samples were identified by André Paviotti Fontana, a botanist from Centro de Recuperação de Áreas Degradadas da Caatinga (CRAD). A voucher specimen (6443) was deposited at the Herbarium Vale do São Francisco (HVASF) of the Federal University of San Francisco Valley (UNIVASF).

\subsection{Extraction}

The dried and powdered leaves (1196 g) were macerated with ethanol $95 \%$ at room temperature for $72 \mathrm{~h}$. The extractive solution was concentrated under vacuum in a rotatory evaporator oven at $50{ }^{\circ} \mathrm{C}$, producing $64 \mathrm{~g}$ of crude ethanol extract (Es-EtOH). The EsEtOH was suspended in a mixture of $\mathrm{H}_{2} \mathrm{O}: \mathrm{MeOH}(7: 3)$ and extracted successively with hexane (Hex), chloroform $\left(\mathrm{CHCl}_{3}\right)$ and ethyl acetate (AcOEt) in crescent order of polarity to obtain the respective fractions (Es-Hex, Es- $\mathrm{CHCl}_{3}$ and Es-AcOEt). Subsequently, all fractions were dried in an oven at $40^{\circ} \mathrm{C}$ for $1 \mathrm{~h}$ for complete elimination of solvent. The dried extracts were used to perform all tests in this study.

\subsection{Total phenolic content}

Total phenolic contents were assayed using the Folin-Ciocalteu reagent, it is based on the method reported by Slinkard and Singleton ${ }^{6}$ with modifications. Total phenolic contents of the extracts (three replicates per treatment) were expressed as mg gallic acid equivalents per gram ( $\mathrm{mg} \mathrm{GAE} / \mathrm{g}$ ) through the calibration curve with gallic acid. The calibration curve range was $50-1000 \mathrm{mg} / \mathrm{l}$ $\left(R^{2}=0.9907\right)$. All samples were performed in triplicates.

\subsection{Determination of total flavonoid content}

Total flavonoid content was determined by using a colorimetric method described previously. ${ }^{7}$ The results were expressed as mg of catechin equivalents per gram of extracts $(\mathrm{mg} \mathrm{CE} / \mathrm{g}$ ) through the calibration curve with catechin $\left(R^{2}=0.9948\right)$. The calibration curve range was $50-1000 \mathrm{mg} / \mathrm{l}$.

\section{5. $D P P H$ free radical scavenging assay}

The free radical scavenging activity was measured using the 2,2diphenyl-1-picrylhydrazil (DPPH) assay. ${ }^{8}$ The absorbance values were measured at $518 \mathrm{~nm}$ and converted into the percentage antioxidant activity (AA) using the following formula: AA $\%=[$ (absorbance of the control - absorbance of the sample) $]$ absorbance of the control] $\times 100$. Ethanol $(1.0 \mathrm{ml})$ plus plant extracts solutions $(2.5 \mathrm{ml})$ were used as a blank. DPPH solution $(1.0 \mathrm{ml})$ plus ethanol $(2.5 \mathrm{ml})$ was used as a negative control. The positive controls (ascorbic acid, BHA and BHT) were those using the standard solutions. Assays were carried out in triplicate.

\section{6. $\beta$-Carotene bleaching test}

The $\beta$-carotene bleaching method is based on the loss of the yellow colour of $\beta$-carotene due to its reaction with radicals formed by linoleic acid oxidation in an emulsion. ${ }^{9}$ The rate of $\beta$-carotene bleaching can be slowed down in the presence of antioxidants. Ascorbic acid, BHA and BHT were used as positive control. In the negative control, the extracts were substituted with an equal volume of ethanol. The antioxidant activity (\%) was evaluated in terms of the bleaching of the $\beta$-carotene using the following formula: \% Antioxidant activity $=\left[1-\left(A_{0}-A_{\mathrm{t}}\right) /\left(A_{0}^{0}-A_{\mathrm{t}}^{0}\right)\right] \times 100$; where $A_{0}$ is the initial absorbance and $A_{\mathrm{t}}$ is the final absorbance measured for the test sample, $A_{0}^{0}$ is the initial absorbance and $A_{\mathrm{t}}^{0}$ is the final absorbance measured for the negative control (blank). The results are expressed as percentage of antioxidant activity (\% AA). Tests were carried out in triplicate.

\subsection{Determination of the maximum absorption wavelength and Sun Protection Factor (SPF) in vitro}

For determining of the maximum absorption wavelength $\left(\lambda_{\max }\right)$, the dried extracts were diluted in absolute ethanol, obtaining concentrations of 5, 25, 50 and $100 \mathrm{mg} / \mathrm{l}$. Subsequently, was performed spectrophotometric scanning at wavelengths between 260 and $400 \mathrm{~nm}$, with intervals of $5 \mathrm{~nm}$. The readings were performed using $1 \mathrm{~cm}$ quartz cell, and ethanol used as blank. Calculation of SPF was obtained according to the equation developed by Mansur et $\mathrm{al}^{2}$ :

$\mathrm{SPF}_{\text {spectrophotometric }}=\mathrm{CF} \times \sum_{290}^{320} \mathrm{EE}(\lambda) \times I(\lambda) \times \operatorname{Abs}(\lambda)$

where: EE $(\lambda)$ - erythemal effect spectrum; $I(\lambda)$ - solar intensity spectrum; Abs $(\lambda)$ - absorbance of sunscreen product; CF correction factor $(=10)$. The values of $\mathrm{EE} \times I$ are constants. They were determined by Sayre et al. ${ }^{10}$

\subsection{Statistical analysis}

The data obtained were analyzed using the GraphPad Prism ${ }^{\circledR}$ version 5.0 and expressed as mean \pm S.D. The $\mathrm{IC}_{50}$ values were calculated by linear regression. Statistically significant differences were calculated by the application of Student's $t$-test. Values were considered significantly different at $p<0.05$.

\section{Results}

Table 1 summarizes the results from the quantitative determination of phenolic and flavonoids as well as the effect of extracts from E. spectabile, ascorbic acid, BHA and BHT on the DPPH free radical scavenging and $\beta$-carotene-linoleic acid bleaching test.

The total phenolics content of the plant extracts was determined by the Folin-Ciocalteu method. This method for total phenol is useful in order to know the efficiency of extraction of phenolic in solvents. The most significant total phenolic content was of $188.50 \pm 27.50 \mathrm{mg}$ of gallic acid equivalent $/ \mathrm{g}$ for $\mathrm{Es}-\mathrm{CHCl}_{3}$. The level

Table 1

Total phenolics (TP), total flavonoids (TF) and antioxidant activity of dried extracts from the leaves of Encholirium spectabile.

\begin{tabular}{lclll}
\hline Sample & TP $(\mathrm{mg} \mathrm{GAE} / \mathrm{g})$ & $\mathrm{TF}(\mathrm{mg} \mathrm{CE} / \mathrm{g})$ & $\begin{array}{l}\mathrm{DPPH} \\
(\mathrm{IC} 50, \mu \mathrm{g} / \mathrm{ml})\end{array}$ & $\begin{array}{l}\beta \text {-Carotene } \\
(\% \mathrm{AA})\end{array}$ \\
\hline Es-EtOH & $42.33 \pm 6.88$ & $53.53 \pm 10.09$ & $39.24 \pm 2.83$ & $42.25 \pm 1.65$ \\
Es-Hex & - & - & $>243$ & $63.54 \pm 1.01$ \\
Es-CHCl & $188.50 \pm 27.50$ & $129.70 \pm 4.59$ & $25.35 \pm 4.35$ & $71.83 \pm 0.38$ \\
Es-AcOEt & $93.92 \pm 1.91$ & $102.80 \pm 1.32$ & $57.64 \pm 2.88$ & $65.77 \pm 5.18$ \\
Ascorbic acid & - & - & $2.34 \pm 0.02$ & $1.89 \pm 1.12$ \\
BHA & - & - & $3.15 \pm 0.24$ & $75.03 \pm 1.92$ \\
BHT & - & - & $37.05 \pm 3.19$ & $79.04 \pm 2.10$ \\
\hline
\end{tabular}

The $\mathrm{IC}_{50}$ values were obtained by interpolation from linear regression analysis with $95 \%$ of confidence level. $\mathrm{IC}_{50}$ is defined as the concentration sufficient to obtain $50 \%$ of a maximum effect estimate in $100 \%$. Values are given as mean $\pm \operatorname{SD}(n=3)$. 
of flavonoids, expressed in catechin equivalents (CE) in $\mathrm{mg} / \mathrm{g}$ of plant extract was of $129.70 \pm 4.59$ for the $\mathrm{Es}-\mathrm{CHCl}_{3}$.

Assays based on the scavenging of DPPH have been widely used to measure the antioxidant activity of different phenolic compounds. This is the most widely reported method for screening of antioxidant activity of many plant drugs. DPPH is one of a few stable available organic nitrogen radicals and has a UV-Vis absorption maximum at $515-518 \mathrm{~nm}$. When a solution of DPPH is mixed with a substance that can donate a hydrogen atom, the reduced form of the radical is generated accompanied by loss of color. ${ }^{11}$ The data showed that the Es- $\mathrm{CHCl}_{3}$ exhibited the most free radical scavenging activity between the extracts tested, with a value of $\mathrm{IC}_{50}$ of $25.35 \pm 4.35 \mu \mathrm{g} / \mathrm{ml}$. Ascorbic acid was the most effective antioxidant, with a value of $\mathrm{IC}_{50}$ of $2.34 \pm 0.02 \mu \mathrm{g} / \mathrm{ml}$.

The antioxidant activity of extracts was also evaluated by the $\beta$ carotene-linoleic acid bleaching method. This method is based on the loss of the yellow color of $\beta$-carotene due to its reaction with radicals formed by linoleic acid oxidation in an emulsion. $\beta$-carotene in this model system undergoes rapid discoloration in the absence of an antioxidant. The rate of the $\beta$-carotene bleaching can be slowed down in the presence of antioxidants. ${ }^{12}$ In this model, the extracts showed moderate to strong antioxidant activity (42.25-71.83\%), and the most active extract was the Es- $\mathrm{CHCl}_{3}$ with percentage of antioxidant activity of $71.83 \pm 0.38$. BHT and BHA were the most effective, while ascorbic acid demonstrated weak activity.

Fig. 1 shows the spectrophotometric absorption profile of the dried extracts of E. spectabile. Analyzing the data can be observed that Es-EtOH, Es- $\mathrm{CHCl}_{3}$ and Es-AcOEt showed characteristic absorption bands in regions UVB and UVA in a concentrationdependent manner, suggesting a possible photoprotective potential. The maximum absorption wavelength $\left(\lambda_{\max }\right)$ for Es-EtOH, Es$\mathrm{CHCl}_{3}$ and Es-AcOEt was 325 (UVA), 325 (UVA) and $260 \mathrm{~nm}$ (UVC), respectively. Es-Hex didn't demonstrate satisfactory absorption.

The SPF in vitro was determined by the spectrophotometric method developed by Mansur (1986) using the UVB region, considered to be the region of greatest incidence during the day in which people are exposed for longer. In Fig. 2, it can be observed that the extracts Es-EtOH and $\mathrm{Es}-\mathrm{CHCl}_{3}$ showed higher SPF at concentration $100 \mathrm{mg} / \mathrm{l}(7.22 \pm 0.61$ and $8.89 \pm 2.11$, respectively) Es-AcOEt and Es-Hex showed low values of SPF ( $4.60 \pm 0.65$ and $1.74 \pm 0.13$, respectively). The results about SPF also showed standard concentration-dependent.

\section{Discussion}

According to the results shown, it was concluded that dried extracts from $E$. spectabile have potent antioxidant activity, mainly by scavenging abilities observed against DPPH radical. Several studies have correlated the potential scavenging free radicals with phenolic and flavonoid contents. ${ }^{13,14}$ Es- $\mathrm{CHCl}_{3}$ showed the lowest $\mathrm{IC}_{50}$ value, which can be explained by the high content of total phenols. Furthermore, Es- $\mathrm{CHCl}_{3}$ presented the highest percentage of antioxidant activity in the $\beta$-carotene bleaching test. The existing data give new information for the antioxidant potential and polyphenolic content of plant species that have not been traditionally used as medicinal plant.

These results corroborate studies with extracts of other species of Bromeliaceae native caatinga biome. Studies performed with extracts from the leaves and flowers of Neoglaziovia variegata that also showed significant antioxidant activity, possibly related to the contents of total phenols and flavonoids totals presented. ${ }^{13}$

It was observed that $\mathrm{Es}-\mathrm{CHCl}_{3}$ showed the best photoprotective activity compared to other extracts. These results can be justified by the high content of flavonoids present mainly in Es- $\mathrm{CHCl}_{3}$. According to the literature, the content of flavonoids produced by a plant is considered an important factor for protecting plants against ultraviolet radiation. ${ }^{15}$ The ultraviolet absorption spectrum of the flavonoids shows in general two peaks of maximum absorption (240-280 $\mathrm{nm}$ and $300-550 \mathrm{~nm}$ ).

Although the test has been carried out in vitro, it was demonstrated that this method correlates well with in vivo tests,

\section{Es-EtOH}

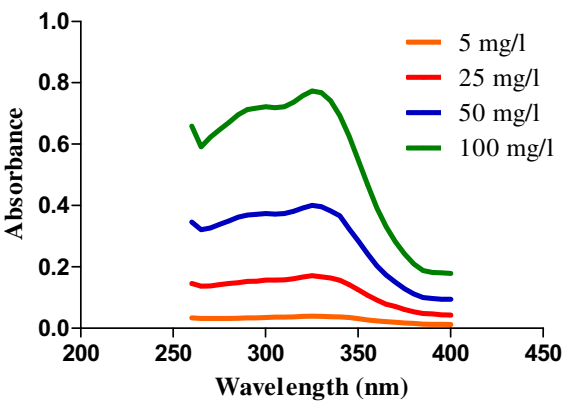

Es- $\mathrm{CHCl}_{3}$

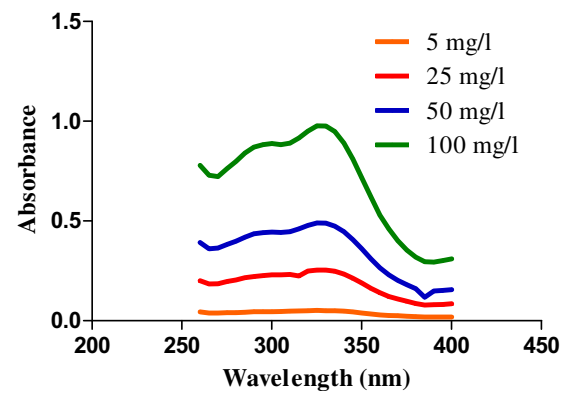

Es-Hex

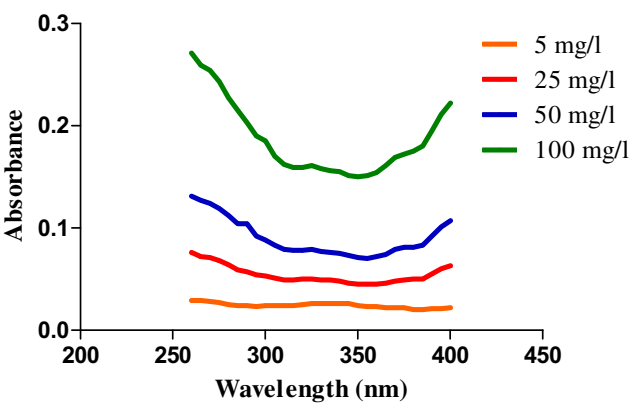

Es-AcOEt

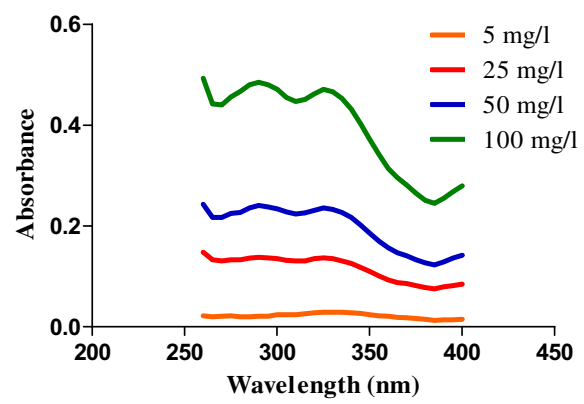

Fig. 1. Spectrophotometric absorption profile of dried extracts of Encholirium spectabile (260-400 nm). 
Es-EtOH

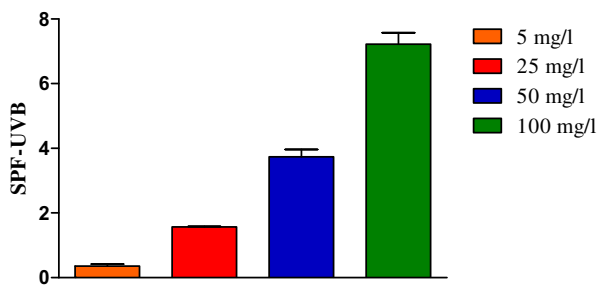

Es- $\mathrm{CHCl}_{3}$

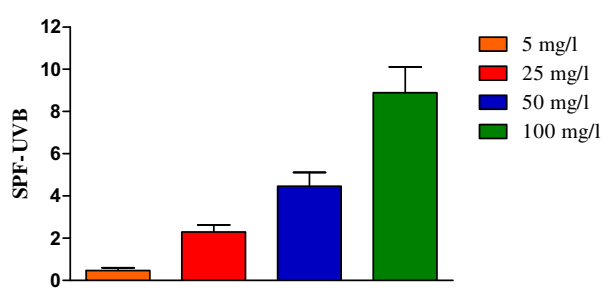

Es-Hex

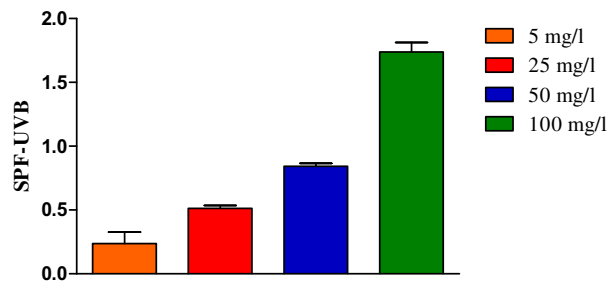

Es-AcOEt

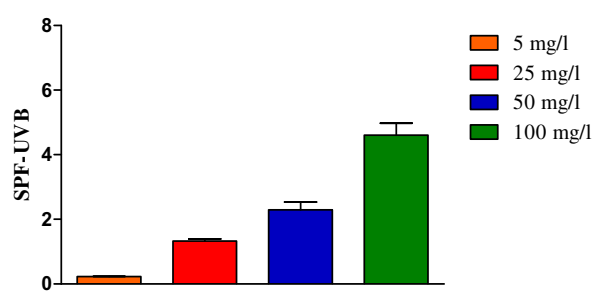

Fig. 2. Sun Protection Factor (SPF) in vitro of the dried extracts of Encholirium spectabile (SPF-UVB).

because relates the absorbance of the substance in question with the erythematogenic effect of radiation and intensity of light at specific wavelengths between 290 and $320 \mathrm{~nm}$ (UVB region).

A study conducted by our research group also showed that dried extracts from leaves of $N$. variegata have photoprotective activity significantly, suggesting that plants of Bromeliaceae family can be considered promising sources of bioactive compounds for cosmetic products. $^{16}$

\section{Conclusion}

In summary, the present study demonstrates that E. spectabile contain phenolic compounds which can serve as natural sources of antioxidants agents. The flavonoids present in the extracts could be responsible by photoprotective effect presented in this study, mainly for the $\mathrm{Es}-\mathrm{CHCl}_{3}$ extract. It shows the possibility to use this extract as sunscreen in pharmaceutical preparations. Further research will be conducted to reach the substance responsible for antioxidant and photoprotective activities of extracts.

\section{Conflicts of interest}

All authors have none to declare.

\section{Acknowledgements}

This work was supported by grants from Brazilian agency CNPq (Process 562801/2010-3). The authors wish to express their thanks to Prof. Dr. José Alves de Siqueira Filho and André Paviotti Fontana of Centro de Referência para Recuperação de Áreas Degradadas (CRAD) for collection and botanical identification of the plant material.

\section{References}

1. Vilela FMP, Fonseca YM, Vicentini FTMC, Fonseca MJV, Amaral MPH. Determination of three ultraviolet filters in sunscreen formulations and from skin penetration studies by high-performance liquid chromatography. Quim Nova. 2011;34:879-883.

2. Mansur JS, Breder MVR, Mansur MCA, Azulay RD. Determinação do fator de proteção solar por espectrofotometria. An Bras Dermatol. 1986;61:121-124.

3. Almeida CF, Ramos MA, Amorim EL, Albuquerque UP. A comparison of knowledge about medicinal plants for three rural communities in the semi-arid region of Northeast of Brazil. J Ethnopharmacol. 2010;127:674-684.

4. Carvalho KIM, Fernandes HB, Machado FDF, et al. Antiulcer activity of ethanolic extract of Encholirium spectabile Mart. ex Schult and Schult f. (Bromeliaceae) in rodents. Biol Res. 2010;43:459-465.

5. Santana CRR, Oliveira-Junior RG, Araújo CS, et al. Phytochemical screening, antioxidant and antibacterial activity of Encholirium spectabile (Bromeliaceae). Int J Sci. 2012;1:1-19.

6. Slinkard K, Singleton VL. Total phenol analysis: automation and comparison with manual methods. Am J Enol Viticult. 1977;28:49-55.

7. Dewanto V, Wu X, Adom K, Liu RH. Thermal processing enhances the nutritional value of tomatoes by increasing total antioxidant activity. J Agric Food Chem. 2002;50:3010-3014.

8. Falcão DQ Costa ER, Alviano DS, Alviano CS, Kuster RM, Menezes FS. Atividade antioxidante e antimicrobiana de Calceolaria chelidonioides Humb.Bonpl. \& Kunth. Braz J Pharmacogn. 2006;16:73-76.

9. Wannes WA, Mhamdi B, Sriti J, et al. Antioxidant activities of the essential oils and methanol extracts from myrtle (Myrtus communis var. italica L.) leaf, stem and flower. Food Chem Toxicol. 2010;48:1362-1370.

10. Sayre RM, Agin PP, Levee GJ, Marlowe E. Comparison of in vivo and in vitro testing of sunscreening formulas. Photochem Photobiol. 1979;29:559-566.

11. Huang D, Ou B, Prior RL. The chemistry behind antioxidant capacity assays. J Agric Food Chem. 2005;53:1841-1856.

12. Kulisic T, Radonic A, Katalinic V, Milos M. Use of different methods for testing antioxidative activity of oregano essential oil. Food Chem. 2004;85:633-640.

13. Oliveira-Júnior RG, Araujo CS, Santana CRR, et al. Phytochemical screening, antioxidant and antibacterial activity of extracts from the flowers of Neoglaziovia variegata (Bromeliaceae). J Chem Pharm Res. 2012;4:4489-4494.

14. Kumar D, Kumar S, Singh J, Narender, Rashmi, Vashistha BD, Singh N. Free radical scavenging and analgesic activities of Cucumis sativus L. fruit extract. J Young Pharm. 2010;2:365-368.

15. Souza TM, Santos LE, Moreira RRD, Rangel VLBI. Avaliação da atividade fotoprotetora de Achillea millefolium L. (Asteraceae). Braz J Pharmacogn. 2005;15:36-38.

16. Oliveira-Júnior RG, Araújo CS, Souza GR, et al. In vitro antioxidant and photoprotective activities of dried extracts from Neoglaziovia variegata (Bromeliaceae). J Appl Pharm Sci. 2013;3:122-127. 